\title{
Consecutive Exotropia after Convergent Strabismus Surgery-Surgical Treatment
}

\author{
Ala Paduca \\ State University of Medicine and Pharmacy “Nicolae Testemitanu”, Chișinău, Moldova \\ Email: paducaa@yahoo.com
}

Received 19 March 2016; accepted 9 May 2016; published 12 May 2016

Copyright (C) 2016 by author and Scientific Research Publishing Inc.

This work is licensed under the Creative Commons Attribution International License (CC BY). http://creativecommons.org/licenses/by/4.0/

(c) (i) Open Access

\begin{abstract}
Purpose: In this study the results of consecutive exotropia surgical treatment by using different surgical technics are presented. Methods: This study included 34 patients, aged 21 to 47 years (mean 27.9), who underwent medial rectus muscle advancement alone or in combination with medial rectus resection and/or lateral rectus recession. The mean interval between original surgery and surgery for consecutive exotropia was 8.5 years (range: 5.5 years to 14 years). Most of patients had 2 and more prior surgeries (73.5\%) sold by an adduction deficit $(47.06 \%)$. Results: The overall mean preoperative exodeviation was 35.12 \pm 10.13 PD. Satisfactory alignment (within 10 PD of orthophoria) was achieved in 20 patients (58.8\%) at 10 days after surgery and 24 patients (70.5\%) at final 6-month follow-up. The most common surgical procedures were unilateral MR advancement and LR recession $-47 \%$. Conclusion: Medial rectus advancement is an effective method of surgical treatment, especially in cases with adduction limitation, but the risk of the eyelid fissure narrowing in cases of MRM advancement more than $5 \mathrm{~mm}$ associated with resection is present. In our opinion for reducing this risk in cases of XT with big angle of deviation, performing a smaller amount of advancement associated with recession of LRM can prevent the development of a such complication.
\end{abstract}

\section{Keywords}

Consecutive Exotropia, Strabismus Surgery, Medial Rectus Advancement

\section{Introduction}

Exodeviation that develops iatrogenically after esotropia surgery is called consecutive exotropia. This deviation occurs according to Von Noorden between 2\% - 8\% [1] while other studies found an incidence ranged from 4\% to $27 \%$ [2] [3]. This surgical complication can develop immediately after surgery or many years and even decades later [4] [5], some risk factors causing its development have been reported by ophthalmologist like high 
hyperopia, amblyopia, vertical deviation, A and V patterns, nystagmus, large medial rectus recessions, restriction of adduction, multiple surgeries, and developmental delay, the failure to evaluate the patient condition preoperatively [2] [3] [5]-[8].

The surgical treatment of this category of strabismus encloses more options on horizontal rectus muscles that are differently used by different authors. Some authors recommend to perform surgeries on muscles which have been already operated in order to avoid manipulation of intact muscles. On the contrary, some surgeons assume that surgery on previously operated muscles is unpredictable and recommend recession of the LR muscles [8]. But, all authors accept that the decision regarding the surgical procedure to be taken involves an assessment of the type and amount of previous surgery and the presence of limitation of adduction (sometimes to the presence of scar traction) or convergence insufficiency [5]. It was established that, large recessions, exceeding $5 \mathrm{~mm}$ of the MRM can produce consecutive exotropia associated with limitation of adduction; large resections of the lateral rectus muscle can cause in contrary a limitation of abduction. Usually recession is indicated for patients with consecutive exotropia with limited adduction after bilateral MRM recession, or in cases that underwent unilateral MRM recession/LRM resection surgery [5]. For patients with divergence excess or exotropia with normal MRM function a bilateral LRM recession is indicated, but it should be avoided in patients with limitation of adduction [5]. But one thing is actual concerning consecutive exotropia-it requires special attention of the orthoptist and surgeons, due to the difficulties in pre-operative assessment, in planning and even performing the surgery [4].

\section{Patients and Methods}

We retrospectively reviewed the records of 34 patients, 15 males and 9 females, with age ranging from 21 to 47 years, mean 27.9, who had undergone surgery for consecutive exotropia. The main complain of this patients was aesthetic problem.

All patients had undergone a complete ophthalmologic and orthoptic examination. Sex, age, corrected preoperative visual acuity (for amblyopia detection-interpreted as a difference in visual acuity of over two lines between the eyes and could not be ameliorated with optical correction), refraction (by retinoscopy spherical equivalent being calculated), number of previous surgeries preoperative and postoperative angle of deviation for distance and for near with Berens prism bar and binocular vision (stero test Lang) were analyzed.

Surgical treatment methods consisted of:

- Unilateral or Bilateral Medial Rectus advancement;

- Combined Medial Rectus advancement and Lateral Rectus recession;

- Combined Medial Rectus advancement with Resection and Lateral Rectus recession. In all patients the muscles elongation test was performed.

All this patients had been followed up for 10 days to 6 month after surgery. The postoperative results were defined as being successful when alignment within $10 \mathrm{PD}$.

Written informed consent to participate in this study was obtained from all patients.

The data were analyzed by Microsoft Excel 2003 (descriptive statistic calculation, standard deviation).

\section{Results}

We tried to find out about the previous oculomotor situation and surgery that patients included in our study had already undergone, the number of operations performed before the Medial Rectus Muscle (MRM) advancement. Almost of patients (22) were operated for convergent squint between 3 and 5 years of age (mean 4.6 years). Multiple surgeries had been performed in $73.5 \%$ (bimedial medial rectus recession and mono or bilateral resection of lateral rectus) and only 9 patients had been operated only once (Table 1).

Refractive status of our patients showed a high degree of hyperopia ( $\geq 3.5 \mathrm{D})$ in only $8.8 \%$ (3) cases, a myopia between $-1.75--3.0 \mathrm{D}$ in $11.8 \%$ (4) cases. The other patients $(79.4 \%)$ had a refractive error between $+3.0 \mathrm{D}$ and $-1.5 \mathrm{D}$. A high degree of anisometropia, more than $2 \mathrm{D}$, was also not found.

Amblyopia was found in $67.6 \%$ of our cases, in $38.2 \%$ it was a moderate one (Table 2).

Prior to surgery 23 patients had a similar exotropic angle for distance and for near. A difference of at least 10PD was found in 11 cases (10 with an angle larger for near, and 1 larger for distance). Mean of deviation being $35.12 \pm 10.13 \mathrm{DP}$.

Sixteen patients (47.06\%) had a monocular or binocular limitation of adduction.

During surgery, the medial rectus muscle was found at a mean of $12.9 \mathrm{~mm}$ from the limbus (ranged from 5.5 
Table 1. Number of prior strabismus surgeries.

\begin{tabular}{cc}
\hline Number of strabismus surgeries & Patients with consecutive XT (no. and \%) \\
\hline 1 & $9(26.5 \%)$ \\
2 & $17(50 \%)$ \\
\hline 2 & $8(23.5 \%)$ \\
\hline
\end{tabular}

Table 2. Amblyopia frequency.

\begin{tabular}{cc}
\hline Degree of amblyopia & Number of patients and \% \\
\hline Presence of amblyopia & $23(67.6 \%)$ \\
Absence of amblyopia & $11(32.4 \%)$ \\
\hline
\end{tabular}

Table 3. Surgical procedures performed according to the degree of deviation.

\begin{tabular}{ccc}
\hline $\begin{array}{c}\text { Degree of } \\
\text { deviation }\end{array}$ & Surgical procedure & Number of patients \\
\hline 15 PD - 25 PD & Mono or bilateral MRM advancement & 7 \\
25 PD - 40 PD & Monolateral MRM advancement + resection Or & 4 \\
40 PD - 55 PD & Monolateral MRM advancement + recession & 14 \\
$\geq 55$ PD & Unilateral MRM advancement + resection + recession of LRM & 4 \\
\hline
\end{tabular}

$\mathrm{mm}$ to $8.2 \mathrm{~mm}$ ).

Considering that $1 \mathrm{~mm}$ medial rectus advancement corrected about $4 \Delta$ of exotropia in 16 cases an unilateral MR advancement and LR recession were performed, followed by unilateral MR advancement/resection (5), unilateral MR advancement/resection and LR recession (4), unilateral MR advancement (2), and bilateral MR advancement (5) (Table 3).

The mean advancement of Medial Rectus Muscles was $5.9 \mathrm{~mm}$. Lateral rectus recession varied from $5 \mathrm{~mm}$ to $8 \mathrm{~mm}$. The postoperative results were controlled 10 days, three month and six month after operation. The success rate in our series was $70.6 \%$ at the final follow-up within $10 \Delta$ of orthophoria, the mean postoperative angle at 6 month of follow-up being $8.3 \pm 5.8 \mathrm{PD}$ (Figure 1). The average reduction of the angle was respectively 31.5 $\pm 7.1 \mathrm{PD}$ of the preoperative angle.

Meanwhile in cases of advancement more than $5 \mathrm{~mm}$ associated with resection we noticed the development of another cosmetic problem-eyelid fissure narrowing. That's why a routine recession of the antagonist may therefore also be required in order to avoid the development of such kind of complication.

\section{Discussion}

According to our study multiplies previous surgeries, limitation of adduction are risk factors in development of consecutive XT. In cases of late consecutive exotropia, various surgical techniques can lead to development of divergence as: large medial rectus recession; large resection of one lateral rectus and engagement of inferior oblique during lateral rectus resection. Even if we were not able to establish the type and amount of previous performed surgeries, we found out an excessive amount of surgery (the mean recession of medial rectus muscles was 12.9 from limbus), that led to adduction limitation and the development of the consecutive exodrift.

In our study we did not have patients with high degree of hyperopia witch according to some publication has been thought to be an important risk factor in producing a consecutive exotropia [2]. Amblyopia-another factor witch increase the risk of developing consecutive XT was found in $67.6 \%$ in our series. It is very important that amblyopia be fully treated in childhood and even after surgery the treatment of residual amblyopia should continue as a good visual acuity and binocular vision are factors of postoperative stability and can prevent the later exodrift.

The surgical results have showed a success rate in our series of $70.6 \%$ even though we noticed the development of an exodrift in some cases, averaging $8.8 \mathrm{PD}$ at final follow-up. In our study the advancement exceeds the original insertion of the muscles by maximum $2 \mathrm{~mm}$ in only 2 cases when angle of deviation was bigger than 


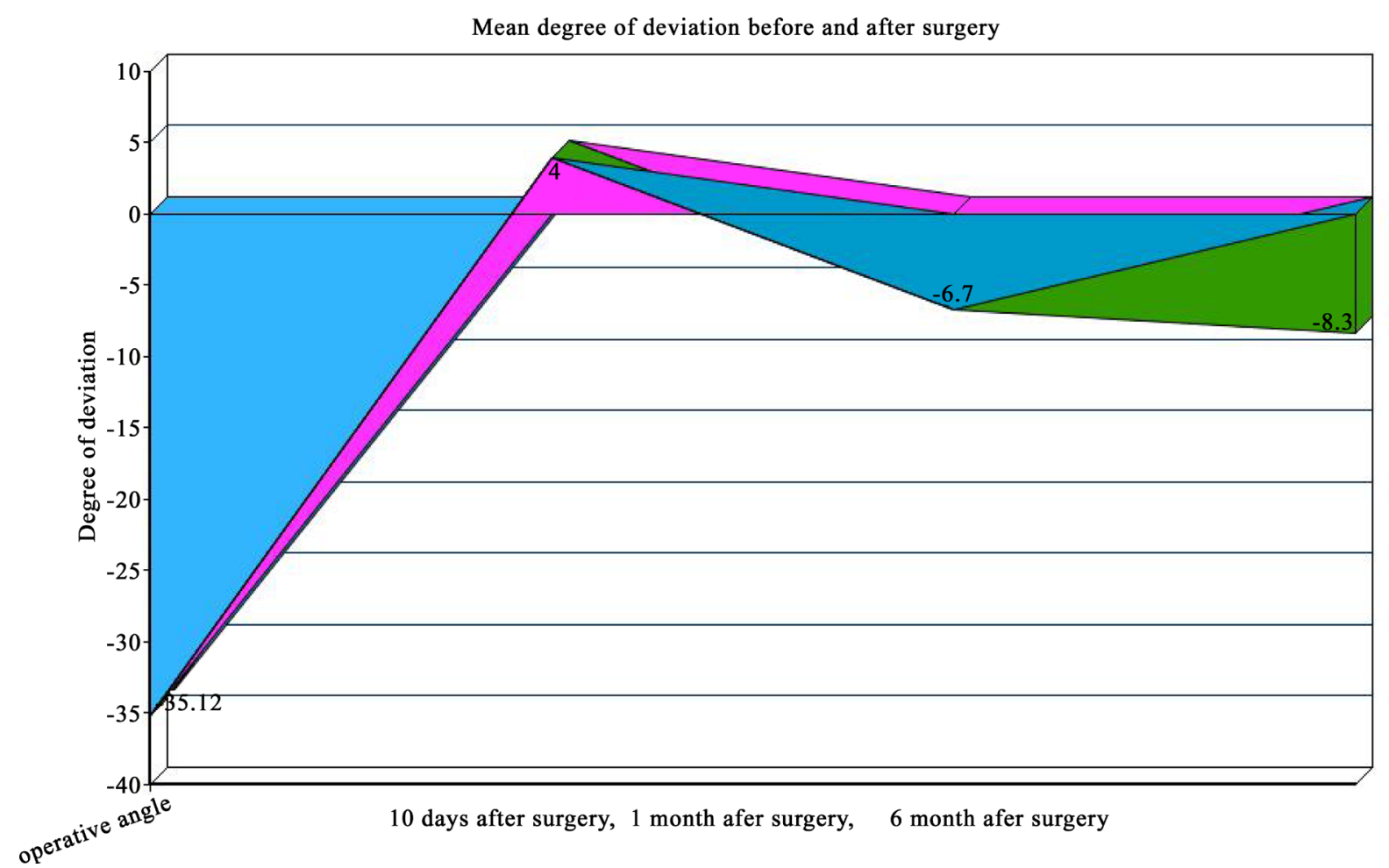

Figure 1. Mean degree of deviation before and after surgery.

55 PD. We performed an unilateral surgery on an amblyopic eye, especially in cases with unilateral amblyopia and literature data also support that most of surgeons approved this approach [5]. According to some author a major effect is expected if a further advancement is performed [5] but in our patients we have noticed the development of an eyelid fissure narrowing after large amount of advancement. That's why in our opinion measurement of eyelid fissure size before performing an advancement is desirable, especially in unilateral surgery.

In our study, the unilateral and bilateral MRM advancements to the physiological insertion corrected exodeviations of about 4 PD per $1 \mathrm{~mm}$ (15 PD and 25 PD respectively). According to Donaldson [9] a suitable ocular alignment immediately after surgery for consecutive exotropia is a small-angle esotropia of 5 to $10 \mathrm{PD}$ as an exotropic drift occurs after consecutive exotropia surgery, usually within the first 6 weeks. The problem of development of a late exodrift after surgery has been reported by many authors [10]-[12]. Kolling G. H. and Schmidt-Bacher A. [13] have noticed the development of an exodrift after three months of follow up, the mean value was -6 degrees, the dose-effect relation was reduced to 1.4 degrees $/ \mathrm{mm}$ from 2 degrees $/ \mathrm{mm}$ operative amount. Yoonae A Cho et al. [12] concluded that the corrective value of Medial rectus advancement is 3 PD per $1 \mathrm{~mm}$; Marcon G.B et al. [11] results were a little bit different, the mean dose-effect being 5 PD at first day after surgery and 4 PD at 6 month. Regarding the choice of surgical technique a lot of authors prefer bilateral lateral rectus recession to all other methods [5] [14] [15]. Gómez De Liaño Sánchez P et al. [16] in a retrospective study on 30 patients who underwent surgery for consecutive exotropia concluded that the technique of choice is a bilateral lateral rectus muscle recession for deviations up to 35 prism diopters, but in cases when the initial deviation exceeds 35 prism diopters the association of an advancement of one or both medial rectus muscles is necessary. He also reported $70 \%$ success rate following bilateral LR recession or unilateral MR advancement. Ohtsuki et al. [17] found out that a single advancement of the MRM to the original insertion correct 23 DP of deviation at distance and 30 DP at near and an bilateral MRM advancement correct 26 DP of deviation at distance and $40 \mathrm{DP}$ at near.

Our surgical results have confirmed that $1 \mathrm{~mm}$ of advancement is able to correct $4 \mathrm{PD}$ of deviation.

\section{Conclusion}

Medial rectus advancement is an effective method of surgical treatment, especially in cases with adduction limi- 
tation, but the risk of the eyelid fissure narrowing in cases of MRM advancement more than $5 \mathrm{~mm}$ associated with resection is present. In our opinion for reducing this risk in cases of XT with big angle of deviation, performing a smaller amount of advancement associated with recession of LRM could avoid such complication.

\section{References}

[1] Kerkhof, Th.B. and Houtman, W.A. (1992) Late Consecutive Exodeviations Section 4: Pediatric Ophthalmology, Strabismus, and Genetics. Documenta Ophthalmologica, 82, 65-71. http://dx.doi.org/10.1007/BF00156995

[2] Folk, E.R., Miller, M.T. and Chapman, L. (1983) Consecutive XT Following Surgery. British Journal of Ophthalmology, 67, 546-548. http://dx.doi.org/10.1136/bjo.67.8.546

[3] Ganesh, A., Pirouznia, S., Ganguly, S.S., Fagerholm, P. and Lithander, J. (2011) Consecutive Exotropia after Surgical Treatment of Childhood Esotropia: A 40-Year Follow-Up Study. Acta Ophthalmologica, 89, 691-695. http://dx.doi.org/10.1111/j.1755-3768.2009.01791.x

[4] Broniarczyk-Loba, A. (2013) Difficulties in Surgical Management of Consecutive Exotropia. Klinika Oczna, 115, 307310.

[5] Pensiero, S., Madonia, M., Paretin, F. and Catalano, D. (2013) Medial Rectus Muscles Advancement in Consecutive Exotropia. Open Journal of Ophthalmology, 3, 37-42. http://dx.doi.org/10.4236/ojoph.2013.32010

[6] Gobin, M.H. (1981) Causes and Treatment of Consecutive Exotropia. Strabismus Symposium Amsterdam, September 3-4, Volume 32 of the Series Documenta Ophthalmologica Proceedings Series, 123-130.

[7] Mohan, K., Sharma, A. and Pandav, S.S. (2006) Unilateral Lateral Rectus Muscle Recession and Medial Rectus Muscle Resection with or without Advancement for Postoperative Consecutive Exotropia. Journal of AAPOS, 10, $220-224$. http://dx.doi.org/10.1016/j.jaapos.2006.01.182

[8] Nabie, R., Gharabaghi, D. and Rahimloo, B. (2008) Bilateral Medical Rectus Advancement versus Bilateral Lateral Rectus Recession for Consecutive Exotropia. Journal of Ophthalmic and Vision Research, 3, 114-117.

[9] Donaldson, M.J., Forrest, M.P. and Gole, G.A. (2004) The Surgical Management of Consecutive Exotropia. Journal of AAPOS, 8, 230-236.

[10] Gesite-de Leon, B. and Demer, J.L. (2014) Consecutive Exotropia: Why Does It Happen, and Can Medial Rectus Advancement Correct It? Journal of AAPOS, 18, 554-558. http://dx.doi.org/10.1016/j.jaapos.2014.08.004

[11] Marcon, G.B. and Pittino, R. (2011) Dose-Effect Relationship of Medial Rectus Muscle Advancement for Consecutive Exotropia. Journal of AAPOS, 15, 523-526. http://dx.doi.org/10.1016/j.jaapos.2011.08.011

[12] Cho, Y.A. and Ryu, W.Y. (2013) The Advancement of the Medial Rectus Muscle for Consecutive Exotropia. Canadian Journal of Ophthalmology, 48, 300-306. http://dx.doi.org/10.1016/j.jcjo.2013.03.003

[13] Kolling, G.H. and Schmidt-Bacher, A. (2006) Management of Consecutive Exotropia-Operative Therapy and Diplopia Testing. Klinische Monatsblätter für Augenheilkunde, 223, 36-41. http://dx.doi.org/10.1055/s-2005-858858

[14] Mangla, D., Simon, J.W., Mangla, N. and Zobal-Ratner, J. (2014) Treatment of Consecutive Exotropia: Unilateral Lateral Rectus Recession Combined with Medial Rectus Advancement or Resection. Journal of Pediatric Ophthalmology and Strabismus, 51, 116-119. http://dx.doi.org/10.3928/01913913-20140205-03

[15] Patel, S.A., Simon, W.J. and Lininger, L.L. (2000) Bilateral Lateral Rectus Recession for Consecutive Exotropia. Journal of AAPOS, 4, 291-294. http://dx.doi.org/10.1067/mpa.2000.109738

[16] Gómez De Liaño Sánchez, P., Ortega Usobiaga, J., Moreno García-Rubio, B. and Merino Sanz, P. (2001) Consecutive Exotropia Surgery. Archivos de la Sociedad Española de Oftalmología, 76, 371-378.

[17] Ohtsuki, H., Hasebe, S., Tadokoro, Y., Kobashi, R., Watanabe, S. and Okano, M. (1993) Advancement of Medial Rectus Muscle to the Original Inserction for Consecutive Exotropia. Journal of Pediatric Ophthalmology and Strabismus, 30, 301-305. 